\title{
CAPÍTULO 11 \\ UM OLHAR SOBRE O SISTEMA DE ESPAÇOS LIVRES EM TRÊS ESCALAS: ESTUDO DE CASO NA ÁREA DO PROGRAMA TERRITÓRIO PAULO FREIRA/ UNESC, CRICÚMA/SC \\ DOI: http://dx.doi.org/10.18616/pgt11 \\ Elizabeth Maria Campanella de Siervi Aline Eyng Savi Mauricio Pamplona Jaqueline Porto da Silva 4. Lays Juliani Hespanhol José Francisco Martins Neto Julia Mendonça Faedo
}




\section{INTRODUÇÃO}

O artigo apresenta a integração de resultados parciais de estudos desenvolvidos pelo Grupo de Pesquisa Sistema de Espaços Livres de Criciúma ligado ao curso de Arquitetura e Urbanismo/UNESC. O recorte utilizado pelas pesquisas se localiza na Grande Santa Luzia, na área do "Programa Território Paulo Freire/UNESC"1.

No "Programa Território Paulo Freire", todos os projetos retratam as necessidades da população envolvida, entendidas a partir de visitas prévias de grupos de professores e acadêmicos com lideranças comunitárias dos bairros da Grande Santa Luzia, Criciúma, Santa Catarina, Brasil.

As investigações do grupo de pesquisa supracitado são: "ESPAÇOS LIVRES PÚBLICOS NA CIDADE EDUCADORA: conceitos, metodologias e instrumentos aplicados ao contexto da acessibilidade na Arquitetura e do Urbanismo tendo como área piloto da Grande Santa Luzia, em Criciúma, Santa Catarina" PIBIC/UNESC/2016; "Espaços livres públicos: acessibilidade para todos" PIBIC/UNESC/2016; "Contribuição das áreas protegidas no sistema de espaços livres da Grande Santa Luzia, Criciúma/SC", PIC/ UNESC/2016; e "Sistema de espaços livres na Região da Grande Santa Luzia, Criciúma/SC: contribuições para inserção da comunidade na qualificação do espaço urbano municipal".

O ponto de partida desses estudos é vinculado ao conceito de espaços livres que pode ser analisado da escala regional a urbana. Essa base conceitual considera que o "espaço" é formado por "ambientes construídos" e "espaços livres de construção" (LIMA et al., 1994) e na Figura

1 O Programa Território Paulo Freire é uma ação de extensão comunitária realizada pela UNESC a partir de projetos que desenvolvem atividades de ensino-pesquisa-extensão numa área territorial específica definida no entorno da universidade. Adota o caráter socioeducativo apoiando-se na pedagogia dialógica do educador Paulo Freire. Os projetos de extensão são nas áreas: ambiental, saúde, educação, sociais aplicadas, economia solidária, entre outras. Nestes 3 anos de atividade se envolveram mais de 100 integrantes dos projetos, entre professores e estudantes e aproximadamente 30.000 pessoas das comunidades. 
1 demonstra essa diferença. Por exemplo: no ambiente urbano, são espaços construídos as edificações e os não construídos os quintais, jardins, ruas, avenidas, praças, parques, rios, matas, mangues, praias urbanas, ou simples vazios urbanos (MAGNOLI, 1982). A localização, acessibilidade e distribuição dessas estruturas formam um complexo sistema de conexões com múltiplos papéis urbanos e caráter público ou privado (MACEDO; CUSTÓDIO, et. al., 2009).

Figura 1 - Ilustração explicativa da configuração dos espaços livres de edificação na cidade
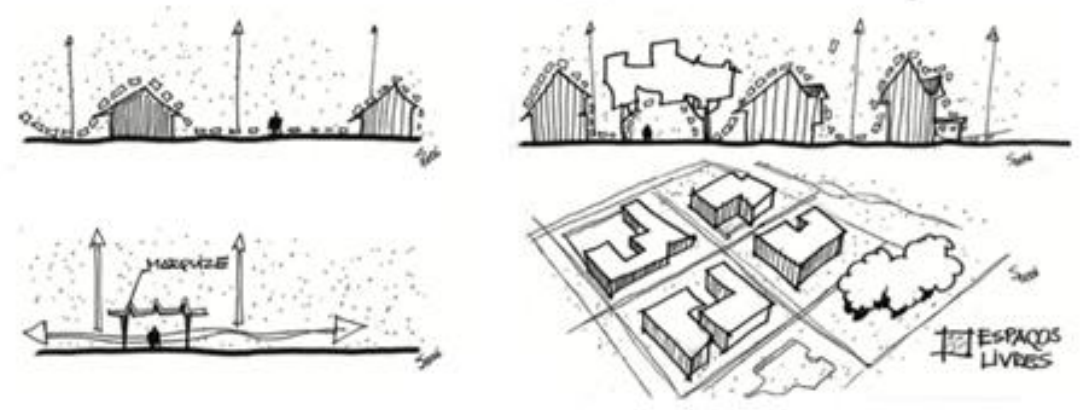

Fonte: Hijioka et al., 2007.

Na análise da paisagem, essa abordagem possibilita a construção de um quadro multiescalar para a leitura dos espaços em suas diferentes interseções: do macroescala, como no caso da região, passando pela mesoescala, como nas observações municipal e urbana, chegando à microescala, no contexto local, observando-se bairros e quadras, permitindo um maior detalhamento de microespaços, por exemplo, as calçadas. 0 desafio desta proposta de leitura ampliada é aplicar, de forma integrada, diferentes métodos de levantamento de dados, de análise e de diagnóstico, adequando-os à escala em questão (SIERVI, 2015; PATRíCIO 2005).

Buscando avançar nesse tipo de abordagem integrada, o artigo apresenta os resultados preliminares dos estudos realizados pelo Grupo 
de Pesquisa na perspectiva desta leitura ampliada do sistema de espaços livres visto como recurso para compreender o desenho urbano municipal, como definidor de conceito de urbanidade na escala comunitária e como vetor de qualidade da infraestrutura urbana, promovendo mobilidade, acessibilidade espacial e numa escala maior, inclusão social e cidadania².

\section{SISTEMA DE ESPACCOS LIVRES DESENHANDO A REGIÃO E A CIDADE}

A escala regional, sob o domínio antrópico, é composta de uma série de componentes organizativos espaciais, correlacionados ou não, a partir da forma e da cobertura espacial que abrange. A região como uma área ou território de caráter contíguo e perfeitamente localizado e individualizado tem na mobilidade o sistema viário como um dos principais fatores que permite os fluxos de atividades econômicas e sociais em forma de rede. Tal rede altera, em última instância, o espaço original a partir de sua configuração em eixos e que, por sua cobertura espacial, determina a organização do território em termos de sua valoração.

De acordo com Santos, os:

[...] espaços são instâncias de manifestação das sociedades em estreita interação com o suporte ecológico, criando e recriando formas - configurações -, as quais representam as maneiras selecionadas em cada tempo e

2 A concepção de cidadania considerada se estabelece a partir da perspectiva freiriana. Para esse autor, embora a cidadania possa assumir formas múltiplas, ela se forma a partir das relações sociais. São as pessoas, os sujeitos sociais, que lhe dão formas e características particulares de acordo com sua consciência e tipo de sociedade na qual se assume ou se insere. Nesse sentido, Freire coloca tipos distintos de consciência: uma consciência intransitiva, que caracteriza uma cidadania importada, em que a realidade é vista a partir do que aconteceu em outras sociedades; outra consciência transitiva ingênua, que vive de conquistas e realizações do passado; e uma consciência transitiva crítica, em que a cidadania é percebida de forma histórica, construída na democracia, e portanto, é aberta ao diálogo, à participação social (GADOTTI, 2009). 
lugar pelas sociedades para promover sua existência. E, se cada localidade, salvo melhor juízo, não detém todas as condições materiais e humanas capazes, sozinhas, de prover as condições de subsistência, seja em função da escassez, seja das dificuldades naturais de apropriação dos recursos disponíveis, seja por sua indisponibilidade ou suficiência, necessário se faz haver interação, trocas e cooperação entre as localidades e entre as populações que as habitam, dos recursos socioespaciais disponíveis (2017, p. 23).

A localização de atividades atratoras na escala regional, assim como na urbana, e as suas conexões são indissociáveis dos diversos sistemas que se tornam complexos ao se dispersarem e adensarem pelo território. Assim, há que se criticar no planejamento e desenho nas escalas urbana e regional a estruturação do território regional sob a lógica funcional, interligando e permitindo a disposição das atividades econômicas principais e não levando em conta a organização da totalidade territorial (HERCE, 2017).

Nesse âmbito, os espaços livres são entendidos como aqueles para além da edificação e na escala regional os preponderantemente interurbanos: as áreas de com elevações e suas encostas, a rede hidrográfica etc. Não caracteriza necessariamente um continuum, nem um conjunto homogêneo, o que, nesses casos, formaria um SEL, porém com uso livre, público, coletivo e não "necessariamente funcional no sentido de pré-programada, ainda que programas sejam desejáveis em algumas escalas". Ainda segundo os espaços livres, não têm necessariamente uma apropriação física funcional, mas também podem ter características de paisagem e ambiental. Daí entender-se que espaços livres são mais do que áreas verdes de passeio, lazer e ou repouso, em contraponto a pensamento anterior (SANTOS, 2017, p. 30).

Ainda de acordo com Santos, a: 
[...] paisagem regional e os espaços livres fazem parte de uma única e mesma dimensão, na qual cabe estudar diversas, múltiplas e diferentes escalas, conforme suas especificidades. Sem, contudo, perder de vista a noção de todo articulado. Isso coloca a necessidade de avançarse no conceito de interação escalar. Esta pode ser compreendida inicialmente como a imbricação entre o geral e o particular, resultado de um movimento pendular que transita do geral para o particular e do particular para o geral, uma abordagem de análise para compreender essas duas instâncias enquanto dimensões complementares, ainda que específicas (2017, p. 30).

Os espaços livres desempenham importantes funções, e, de acordo com Landim (2004), a função básica dos espaços livres na escala regional é justamente possibilitar a circulação, ou seja, os espaços livres são um elemento de aglutinação entre os diversos tipos de espaços, permitindo, dessa forma, a apreensão, a compreensão e o uso da terra. Os "espaços cheios" são percebidos a partir dos espaços vazios, em uma relação dialética, em que um constrói o outro.

A região assume diversas formas de delimitações conforme a adoção de critérios ou metodologia, tais como: região por características urbanas conturbadas ou metropolitanas, como expressão econômica e populacional; e por características físicas, como uma bacia hidrográfica.

Dentro da caracterização de regiões, observa-se a sua ocupação na forma de concentração ou dispersão e ainda centro periferia em última instância partir das caraterísticas de ocupação e concentração urbana.

Procura-se aqui analisar a questão da mobilidade em relação à escala regional em que se insere a cidade de Criciúma. Tal território e espacial pode ser adotado conforme se trata a cidade como um polo regional da região sul catarinense. Dessa forma, numa primeira análise toma-se a bacia hidrográfica do rio Araranguá como a região de inserção das relações espaciais. 
O município e a mancha urbana de Criciúma se dividem entre as bacias do rio Araranguá e Urussanga. A figura também dá conta das interações viárias regionais que historicamente construíram as ligações e percursos de exploradores vicentistas, tropeiros, açorianos e demais colonos europeus.

A Figura 2 mostra o resultado da interação exploratória atual a partir dos usos da terra e que denota a ocupação a partir de duas vertentes: a urbana/mineradora e a agricultura. A primeira em grande parte associa a ocupação urbana associada à exploração do carvão mineral que ocorreu em grande escala a partir da metade do século XX, principalmente no setor nordeste da bacia, tendo Criciúma como polo centralizador dessa atividade (Figura 3). Na segunda, tem-se a disseminação sobre as planícies muito bem drenadas, principalmente a cultura do arroz. Entre esses dois vieses, há o território com pouco antropização, as encostas da Serra Geral de norte a sudeste (Figura 4).

Figura 2 - Uso da terra da bacia do Rio Araranguá

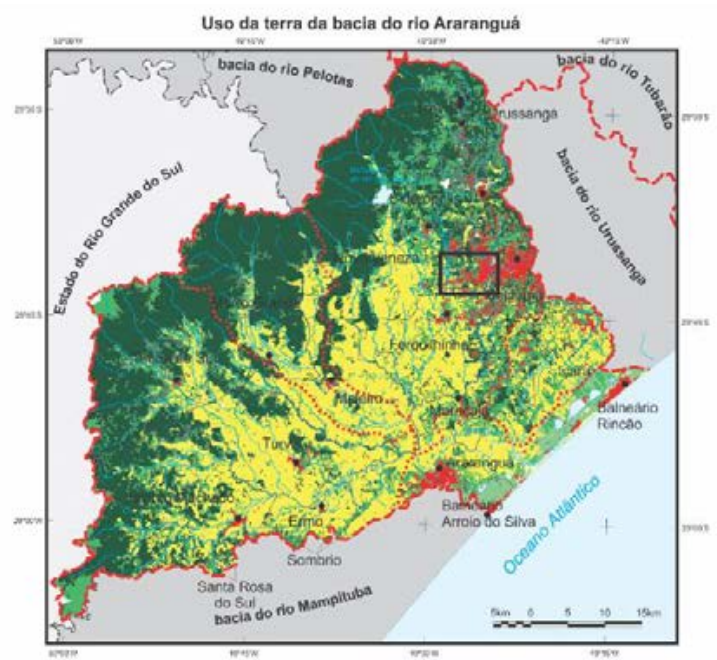

Fonte: Adami e Cunha - Org., 2014.

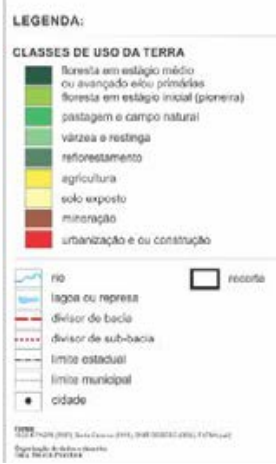


Figura 3 - Hidrografia e sub-bacias do Rio Araranguá

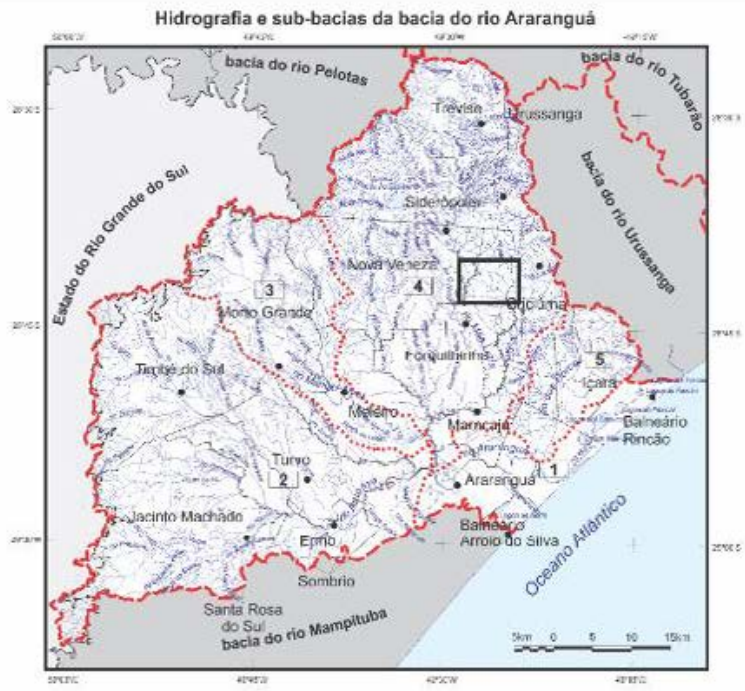

Fonte: Adami e Cunha - Org., 2014.

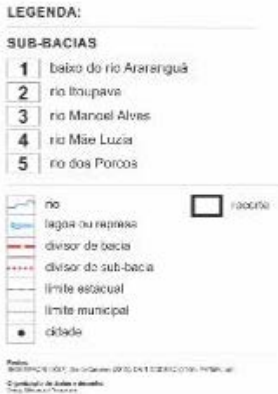

SUB-BACIAS

2 in thoupa

3 no Mancel Alve

4 tu Máe Lucsa

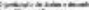

Figura 4 - Hipsometria da Bacia do Rio Araranguá
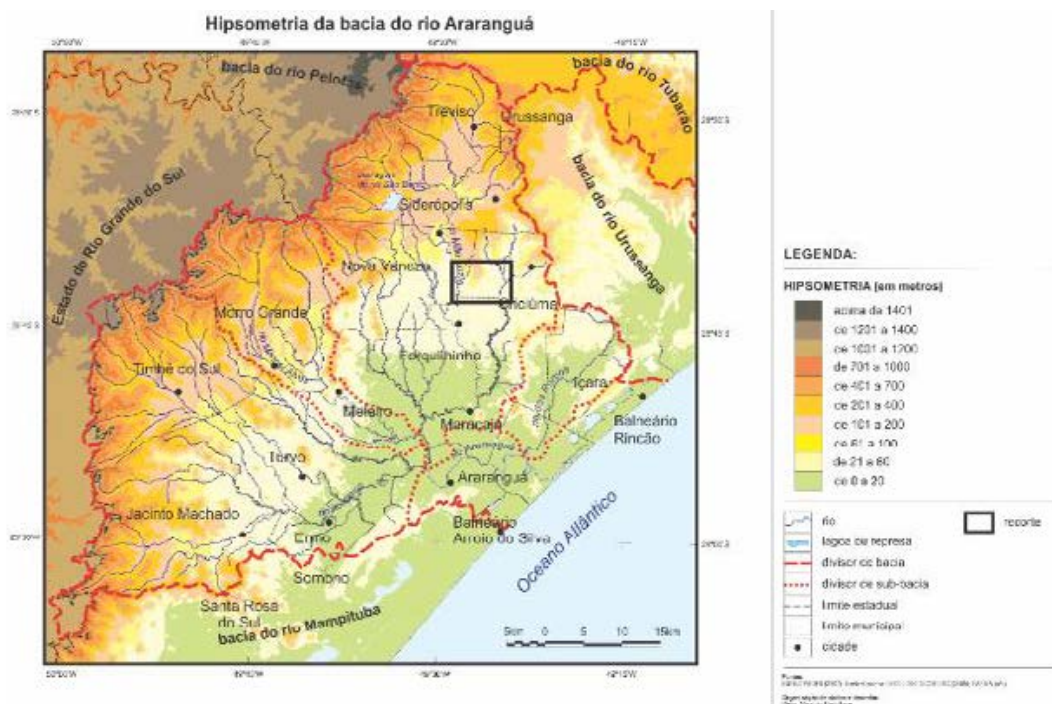

Fonte: Adami e Cunha - Org., 2014. 
Então, nesse meio com essa extensão e diversidade de ocupação, a escala regional:

a. localização os espaços livres conectados pelas intencionalidades capitalistas o que provoca na ampliação para a escala urbana;

b. os entendimentos desses processos dialéticos à formação de diversos SEL regionais, que visem à aglutinação dos diversos espaços segundo suas intenções.

Nas Figuras 1 a 3, também é localizado o recorte de estudo para as escalas do bairro e local, onde em última instância relacionam-se as diversas escalas, em uma causalidade espacial.

O desenvolvimento econômico e urbano de Criciúma e diversas cidades estão ligados à exploração do carvão mineral. Essa condição interfere na conformação dos espaços livres e dos construídos em boa parte de sua malha intraurbana e de sua periferia. Atualmente, a presença do passivo ambiental resultante ainda é evidente, especialmente nos espaços livres resultantes.

A peculiaridade de tais espaços para a Criciúma contemporânea reside justamente na sua origem e na extensão e condição ambiental dela decorrentes. Ou seja, tais áreas representam hoje significativas porções do território e estão, predominantemente, em situação de degradação ambiental.

É nesse contexto geral que o quadro atual mostra a permissividade do planejamento no sentido da ocupação de áreas degradadas e seus entornos (PAMPLONA; TRINDADE, 2015, p. 2).

A região da Grande Santa Luzia tem uma extensão de $19,60 \mathrm{~km}^{2}$, correspondendo a $8,36 \%$ do território municipal, e não foge ao quadro 
descrito acima. Localiza-se a aproximadamente $4,6 \mathrm{~km}$ a sudeste do centro urbano e é formada por oito bairros e nove localidades. É limitada pelos rios Sangão e Mãe Luzia, respectivamente a leste e oeste; o norte limita-se com a bacia do Rio Maina e ao sul tem limita-se com a planície drenada pelos afluentes dos rios Sangão e Mãe Luzia.

A Figura 5 demonstra a ocupação urbana que se desenvolve ao sul e sudoeste na planície de limite sul, ocorrendo de maneira linear junto à antiga estrada Araranguá-Criciúma, atual SC 408, na forma de um vetor de crescimento, no sentido leste-oeste, numa extensão de 5,5 km. A partir da rodovia, as ocupações são perpendiculares de forma descontínua junto à rodovia. A leste, a ocupação é nucleada e acontece de forma mais estruturada e densificada, a oeste do rio Sangão. Tal urbanização ocorre a partir da década de 1950, com a construção de loteamento popular destinado aos mineiros (PAMPLONA; SIERVI, 2016).

Figura 5 - Localização da região da Grande Santa Luzia no município de Criciúma

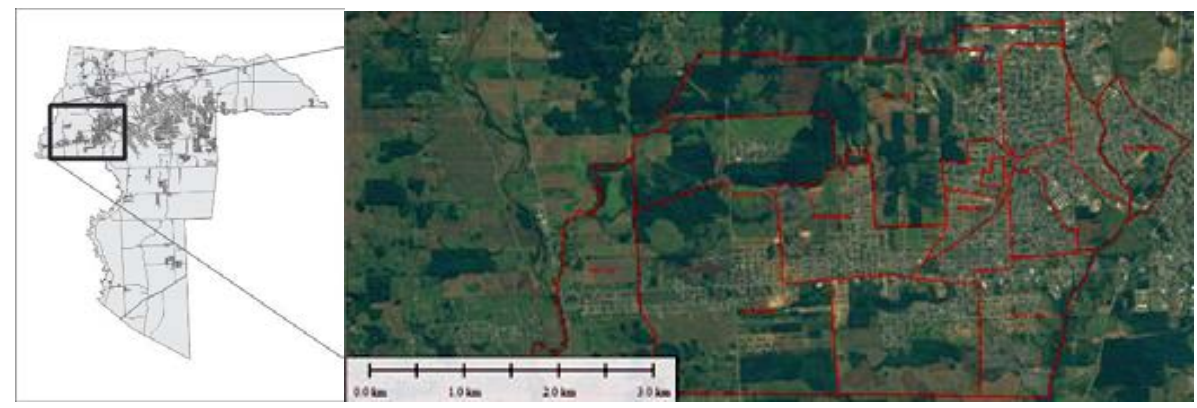

Fonte: Pamplona e Siervi, 2016.

Atualmente, a área se desenvolve numa extensão contínua na mancha urbana de Criciúma a sudeste. Estão incluídos nela grande vazios que em sua maioria são depósitos de rejeito de carvão. Tais espaços são o resultado da exploração a céu aberto no momento da expansão da mineração do carvão refletindo negativamente no ambiente. Na área existia como núcleo de urbanização uma vila operária na então área rural. 
Neste contexto de ocupação da área principalmente pelos interesses da exploração, resultou numa "paisagem de desagregação, com importante impacto na paisagem, na constituição dos espaços públicos e no desenho urbano resultante deste processo de ocupação desordenada (PAMPLONA; SIERVI: 2016, 5).

Dessa forma, a partir do desenvolvimento obtido na região que comporta Criciúma, metodologicamente toma-se a paisagem como a dimensão concreta e perceptível do espaço e no sentido da leitura e da forma que dá a região. Traz-se aqui a noção de paisagem de Santos (1997, p. 30) que explicita ser "o espaço é acumulação desigual de tempos" para reafirmar que também é assim com a paisagem, pois essa é aqui tomada como a dimensão concreta e perceptível do espaço.

Para Santos,

ao adotar-se o entendimento da paisagem como sendo mais do que forma - configuração - forma que informa, pois é produzida, construída socialmente em processos dialéticos, portanto históricos, pode-se afirmar que a paisagem informa pela leitura de suas formas: os tempos, os agentes, os processos e os sistemas que a formaram, formam e aos quais está sujeita em suas próximas transformações (2017, p. 27).

\section{OS ESPAÇOS LIVRES E PÚBLICOS NO BAIRRO: VIVER E CONVIVER COM A COMUNIDADE}

É na escala do bairro que a vida comunitária acontece, principalmente quando estamos pensando na vida cotidiana. Essa vivência pode se dar de diferentes formas, mas ela acontece prioritariamente em espaços onde há possibilidades de se estabelecer interações coletivas, seja na dimensão do morar, do trabalhar, da realização de trocas sociais e econômicas ou na hora de se divertir. 
Nesse contexto, os espaços livres e públicos têm um importante papel agregador. Segundo Queiroga (2014), os espaços livres públicos são bens de propriedade pública que possuem diferentes graus de acesso e de apropriação.

No Brasil, o Código Civil ${ }^{3}$ define as propriedades públicas como: - bens de uso comum do povo: espaços de apropriação pública por excelência (a rua, a praça, o parque urbano, a praia, etc.); - bens de uso especial: destinados a atividades específicas (escolas públicas, postos de saúde, paços municipais, entre tantos outros exemplos); - bens dominicais ou dominiais: os próprios de qualquer ente público passíveis de desafetação (QUEIROGA, 2014, p. 113).

Assim, a rua, a praça, o parque urbano, a praia, as áreas livres nas escolas públicas, nos postos de saúde e nos paços municipais são exemplos que definem o sistema de espaços livres públicos de um bairro. 0 estudo e a valorização desses espaços públicos e livres são fundamentais, uma vez que é neles que boa parte da construção da cidadania acontece, potencializada pelos encontros, trocas e demais atividades que ali acontecem.

Porém, Queiroga (2014) alerta quanto ao enfraquecimento dessa "vida pública" de uma forma geral, sobretudo quando estamos na escala de vizinhança. Esse autor considera que esse fato está se configurando em escala crescente, tanto nos grandes centros como também mais cidades médias. É uma tendência contemporânea de implantação de grandes empreendimentos privados, tais como condomínios horizontais ou verticais, que proveem espaços livres qualificados, embora sejam de caráter privado, ou seja, que oferecem acesso reduzido e controlado a população de uma forma geral. Assim, os espaços de encontro cotidiano, de contato no nível de bairro, se reduzem ao máximo, se limitam aos

3

BRASIL. Lei no 4.771, de 15 de setembro de 1965. Institui o novo Código Florestal. Brasília: Presidência da República. Casa Civil. Disponível em: <http://www.planalto. gov.br/ ccivil_03/leis/L4771.htm>. Acesso em: 17 mar. 2012. 
encontros de calçada com os vizinhos homogêneos que se encontram na parte de dentro da área murada que desenha o condomínio.

É a partir da compreensão desse contexto em constante mutação que o estudo "Espaços livres públicos na cidade educadora: Conceitos, metodologias e instrumentos aplicados ao contexto da acessibilidade na Arquitetura e do Urbanismo em área piloto da Grande Santa Luzia, em Criciúma, Santa Catarina" se desenvolve em nível de PIBIC e PIC (SIERVI, 2016; 2016a).

Os pressupostos da pesquisa consideram que, ao observar os espaços públicos em um dado lugar, as interações estabelecidas e os espaços privados, podemos nos aproximar de um entendimento mais sensível sobre as "formas de viver" de seus moradores. Esse jeito coletivo de habitar o bairro pode ser lido pelas particularidades do morar local, incluindo-se o tipo de relacionamento dos moradores com seu entorno, seu ambiente urbano mais próximo. Nesse sentido, encontram-se caminhos para avançar na análise de componentes para leitura da "Cidade Educadora", estabelecendo relações entre a "qualidade" dos espaços públicos e da cidadania vivenciada nos seus moradores.

Entende-se que esse tipo de análise leva em conta múltiplos fatores que vão desde o histórico da inserção urbana do bairro até as características em que se estruturam a gestão urbana e a oferta de serviços em nível local. Esse cuidado considera que essa "forma de viver" coletiva observada in loco pode não ter sido "escolhida coletivamente", ou culturalmente. Nesse caso, essa "forma de viver" pode, muitas vezes, representar a interação dinâmica entre os desejos e as ofertas reduzidas de espaços de qualidade e de convívio coletivo cidadão (VARGAS, 2016).

4 A concepção contemporânea de "Cidades Educadoras" surge a partir de uma carta lançada, em uma primeira versão, em 1990 na cidade de Barcelona, Espanha, durante o 1ㅇ Congresso Internacional de Cidades Educadoras (CARTA DAS CIDADES EDUCADORAS, 1994). Segundo elementos dessa Carta, a cidade, em sua prática cotidiana educadora, pode gerar e incluir diferentes formas de educação para a cidadania [formal e não formal], seja em atividades no Plano diretor, em proposta e ações da cultura, nas escolas, no lazer ou outros espaços urbanos (SAVI; SIERVI; PAMPLONA, 2017). 


\section{RECONHECENDO O RECORTE DE ESTUDO: ESPAÇOS LIVRES NO PILOTO DO BAIRRO DE SÃO DEFENDE}

A área selecionada para a aplicação de piloto está inserida nas delimitações do Programa Território Paulo Freire/UNESC, na região da Grande Santa Luzia, no Bairro São Defende. Essa delimitação considerou a pré-existência de dois projetos de extensão que atuam nesse contexto ${ }^{5}$, possibilitando a realização de ações integradas, ampliando as condições de aproximação com a comunidade local (Figuras 6 e 7).

Nessa etapa da pesquisa, foi realizada a caracterização dos espaços livres dessa área, a partir de visitas de campo e mapeamento digital, levando em consideração a leitura da morfologia de lotes e das ocupações pelas edificações. Esse levantamento permitiu o mapeamento dos espaços livres privados e públicos da área e identificação de formas de ocupação da área.

Figura 6 - Localização da área piloto e recorte de levantamento inicial na região do território Paulo Freire/UNESC

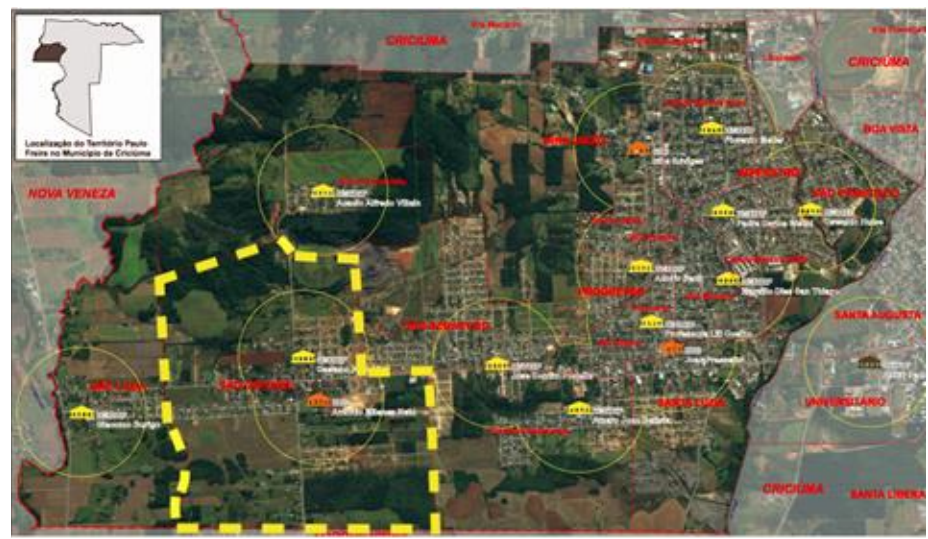

Fonte: Savi, Siervi e Pamplona, 2017.

5 Projeto Caetano Ronchi: qualificação do ambiente escolar, Curso de Arquitetura UNESC/2016-2017; e Projeto Ambiente e Cidadania, Programa Território Paulo Freire/UNESC, 2016-2017. 
Figura 7 - Detalhe da área de recorte de levantamento inicial

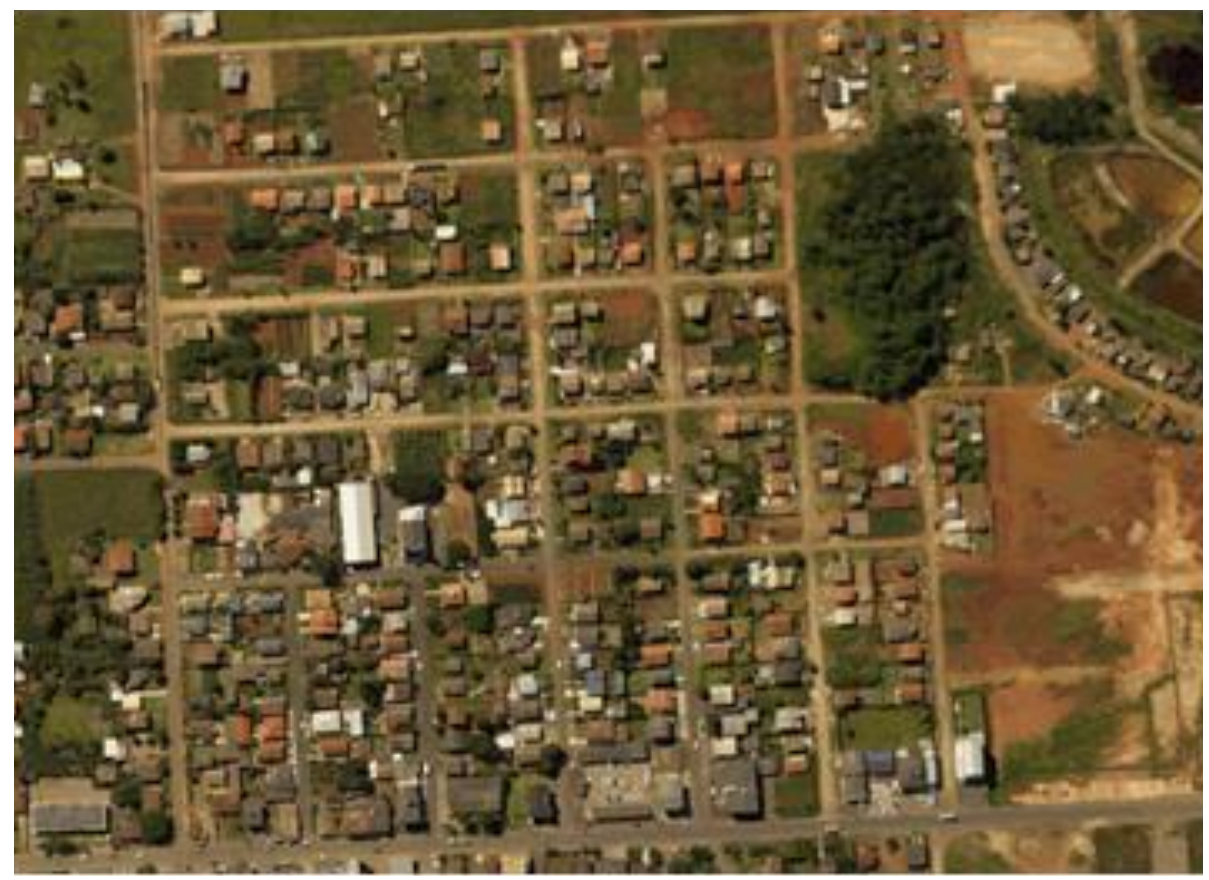

Fonte: Savi, Siervi e Pamplona, 2017.

Verificou-se que a maior percentagem de espaço livre público está definida pelo sistema viário (as calçadas e as ruas) e que outras áreas livres públicas estão restritas às áreas não edificadas de equipamentos públicos ou institucionais do bairro (escola, igreja, centro comunitário). Além disso, no bairro há uma APP, área de preservação permanente, que é uma área estabelecida legalmente na nascente do Santo André, porém que não recebe nenhuma ação do município para garantir sua integridade. Estes espaços estão apresentados na Figura 8. 
Figura 8 - Identificação dos espaços livres públicos, institucionais e legais no recorte da área em estudo

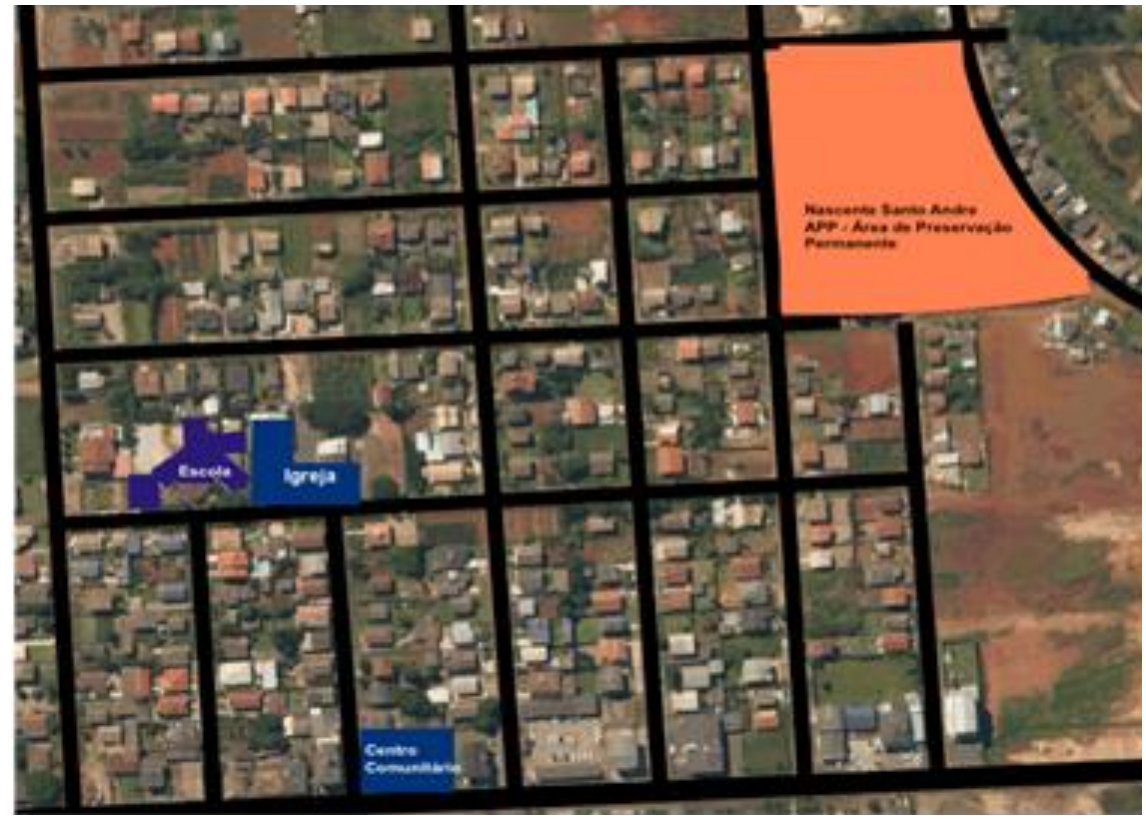

Fonte: Savi, Siervi e Pamplona, 2017.

A partir dessa caracterização inicial, desenvolveu-se a leitura do sistema de espaços livres em nível de bairro que apresentamos a seguir.

\section{ESPAÇOS LIVRES EM NIVEL DE BAIRRO: RECONHECENDO A FORMA DE VIDA LOCAL}

A primeira aproximação do bairro, em nível da paisagem de um sistema de espaços livres, se dá a partir da observação das áreas desativadas da mineração. Verificamos uma situação de abandono das áreas, tanto por empreendedores quanto pelo poder fiscalizador estatal. Esse sentimento se dá porque há determinações legais que ordenam essa recuperação, conforme estabelecido pelo Decreto 97.632/89, que instituiu 
a exigência de um Plano de Recuperação de Área Degradada (PRAD) para a atividade de mineração no Brasil (STIFELMAN, 2005).

A mineração, contudo, apresenta uma peculiaridade: uma vez retirado de seu local de ocorrência natural, em hipótese alguma o minério pode ser reconstruído ou retorna à sua origem, da mesma maneira como se encontrava no estágio anterior da exploração, motivo pelo qual a mineração impõe ao ambiente em geral uma característica de degradação irreversível (STIFELMAN, 2005, p. 540).

No nível de bairro, na área do recorte, vivenciando seus espaços e conexões internos, foi possível identificar três situações que também indicam um importante grau de abandono. A primeira se localiza em área de APP situada na divisa com o bairro Santo André. Essa área é vizinha a uma área de mineração desativada e encontra-se igualmente em estado de abandono público, pois é propriedade da Prefeitura e há nela uma nascente. Outro fato importante é que, dada a configuração da área, há um processo contínuo de invasão para a construção de habitações irregulares, que acontecem na sequência de episódios de queimadas para retirada de vegetação do local (Figura 9).

Figura 9 - Imagem da área de APP mostrando a falta de cercamento, um registro de autoconstrução irregular e um episódio de queimada

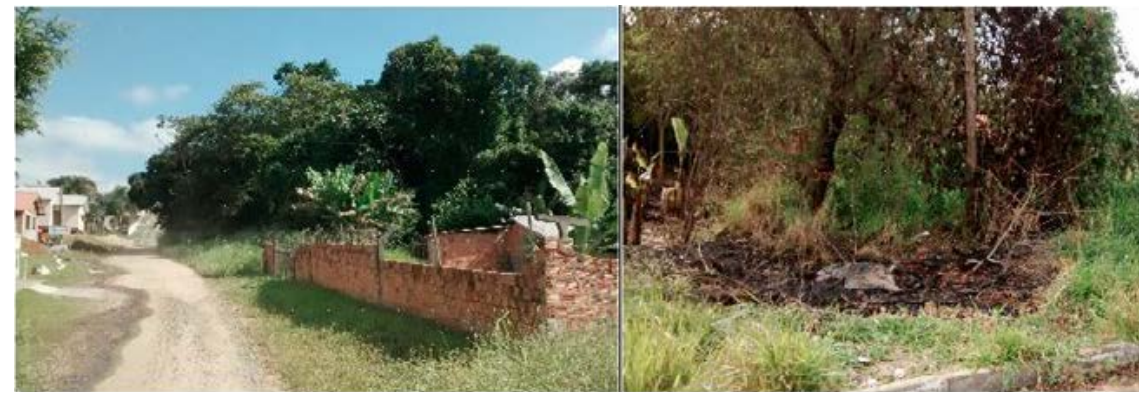

Fonte: GPSEL - Criciúma, 2017. 
A terceira situação em destaque está ligada ao arruamento e às conexões com calçadas e edificações. São encontradas diversas situações que vão desde vias asfaltadas sem a existência de calçadas ou, quando têm, não há acessibilidade, há postes dividindo o passeio, mostrando a falta de padronização, até vias sem calçamento ou qualquer tratamento (Figura 10).

Figura 10 - Diferentes situações das vias e calçadas, demostrando falta de padrão. Calçadas sem acessibilidade, postes implantados no meio de calçadas e passeios públicos inexistentes

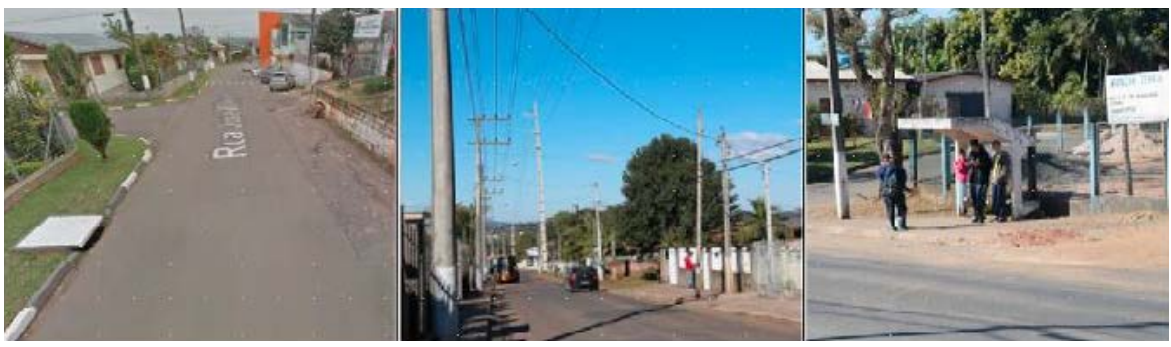

Fonte: GPSEL - Criciúma, 2017.

A leitura da situação dos espaços livres em nível de bairro desenvolveu a caracterização inicial do sistema, abrindo espaço para que se percebe a necessidade de aprofundamento que apoiou a delimitação da abordagem do estudo de acessibilidade desenvolvido dentro do grupo de pesquisa. Indicou ainda a necessidade de integração escalar e abriu fortaleceu a perspectiva educadora dos espaços da cidade (SIERVI, 2016).

\section{ESPAÇOS LIVRES PÚBLICOS NA ESCALA DO COTIDIANO: A ACESSIBILIDADE EM RUA E CALCCADAS}

Um dos espaços livres públicos mais utilizados no dia a dia do cidadão é a calçada, fonte de acesso e conexão entre espaços construídos 
e livres. Responsável pela condução da população, os passeios urbanos ou calçadas deveriam ser lugares agradáveis, seguros para prática da caminhada ou mesmo para outras atividades, como o trabalho, estudo, socialização e circulação, mas acabaram, ao longo dos anos, por se tornar espaços com pouca ou nenhuma acessibilidade. Isso prejudica todo o sistema de mobilidade urbana, sem conferir segurança para a circulação de pedestre, além de isolar uma parte da população (SAVI, 2016).

A acessibilidade é um conceito amplo que supera o senso comum da simples necessidade de uma rampa ou de pisos táteis. É assegurada por leis (e.g. Lei Federal n. 10.098/2000), decretos (e.g. Decreto n. 3.298/1999) e pela Associação Brasileira de Normas Técnicas (e.g. NBR 9050/2015). Para alcançá-la, é necessário que coexistam quatro componentes: deslocamento, orientação espacial, uso e comunicação atendendo às diferentes capacidades (DISCHINGER et al., 2006), de maneira que a ausência de apenas um deles afeta o acesso integral, como apontam Dischinger, Bins Ely e Borges (2009).

O deslocamento envolve a possibilidade de movimento ao longo de trajetos e supõe a ausência de barreiras físicas que impeçam a realização de atividades de forma independente, por exemplo, um poste no meio do percurso. A orientação, por sua vez, traduz o conhecimento de onde se está e para onde se quer ir, a partir do desenho arquitetônico claro e de informações indispensáveis que esclareçam, como pisos guias, placas e sinais sonoros. No uso emerge a possibilidade de exercício das atividades de forma independe, considerando as diferenças e sem a necessidade de um conhecimento prévio, por exemplo, a aplicação normativa dos pisos informativos. A comunicação diz respeito à possibilidade de troca de informações entre pessoas e com os equipamentos, como mapas táteis.

Os espaços livres acessíveis das calçadas devem ser projetados cautelosamente, corroborando autores como Cardoso (1992), Cohen (1998), Conde (1994), Hazan (1994), Ubierna (1994) e Yázigi (2000) sugerem algumas condicionantes como a eliminação de obstáculos; uso de textura especial para advertir o perigo; adoção de pisos não derrapantes; 
adoção de cruzamentos feitos por meio de rampas com cores e texturas diferentes; evitar rampas em sentido diagonal à intersecção; e o estudo preliminar antes da colocação do mobiliário.

Ao viabilizar acessibilidade, cria-se condição essencial para cidadania urbana, através de espaços inclusivos, já que a experiência dos espaços estrutura os padrões de identificação do sujeito com o meio ambiente. Segundo Tuan (1983, p. 10), “[...] experienciar é aprender, compreender; significa atuar sobre o espaço e poder criar a partir dele". Portanto, é necessário que o processo cognitivo se desenvolva através da percepção e da apreensão do espaço para que o indivíduo possa conhecer e agir sobre ele.

\section{ESCALA DE ESTUDO: DESENVOLVENDO A ANÁLISE DAS CALCADAS NO RECORTE}

A pesquisa "Acessibilidade para todos em espaços livres públicos" iniciou com visitas exploratórias ao recorte, em busca de caracterizar os espaços livres e identificar as maiores deficiências. No que tange à acessibilidade espacial, é perceptível que os maiores problemas estão na infraestrutura e no mobiliário urbanos através: da ausência de calçadas ou sua má conservação e execução e falta de calçamento nas vias públicas. Em razão dessa caracterização, a pesquisa definiu como recorte de estudo as calçadas. Afinal, os problemas ali encontrados corroboram para que a cidade seja hostil nas questões de acessibilidade e, dessa maneira, faça o caminho inverso à cidadania urbana.

A metodologia adotada para avaliar a pós-ocupação é participativa com o objetivo de inserir usuários no processo projeto e, com isso, despertar para o assunto da acessibilidade espacial e das pessoas com deficiência e restrição, através dos métodos: Active Design e Passeio Acompanhado. O primeiro método é aplicado através da experiência do avaliador no local (Figura 11), que pode tomar notas, fazer croquis de auxílio e pontuar as calçadas em cada um dos tópicos que é observado. 
Figura 11 - Ilustração da metodologia baseada no Active Design: Shaping the sidewalk experience

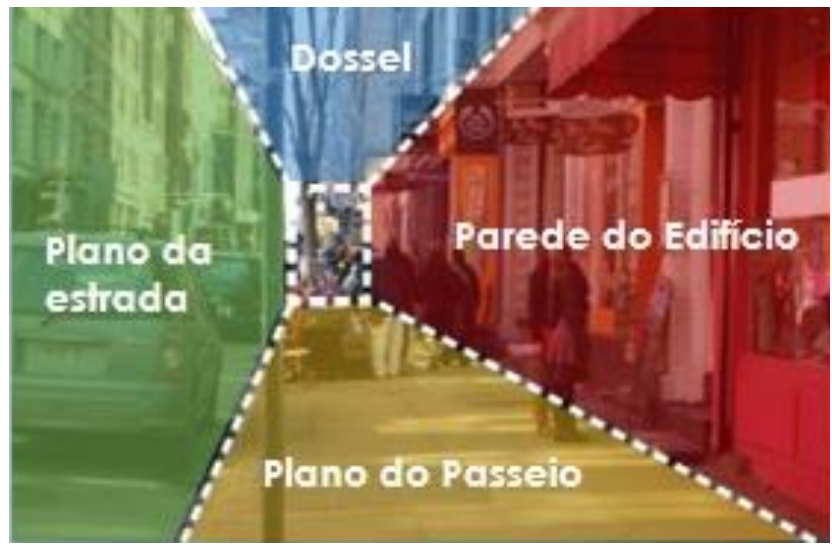

Fonte: Elaborada pelos autores, 2017.

A metodologia é desenvolvida em duas etapas, sendo a primeira "O passeio e suas fases", caraterizada por escolher o local de análise e, assim, com uma perspectiva: marcar os quatro diferentes planos presentes na construção da imagem do passeio - dossel; parede do edifício; plano da estrada; e plano do passeio. A etapa seguinte é chamada de "O olhar do observador", em que se inclui a sensibilidade de um observador, que levanta todos os pontos positivos e negativos de cada plano marcado na etapa anterior. Na pesquisa, foram considerados: segurança, mobiliário urbano e acessibilidade.

Além dessa metodologia, foi utilizada a metodologia dos passeios acompanhados (DISCHINGER, 2000) a fim de aprofundar os estudos no âmbito da acessibilidade, mapeando as condições reais de uso do espaço por parte do usuário, de forma a identificar, no exato momento em que ocorrem as atividades, os aspectos positivos e negativos do lugar.

Para essa etapa de campo, selecionou-se uma rota em que são percebidos os problemas de acessibilidade comuns do recorte, sendo eles: falta de calçamento ou de padrão nos passeios, falta de elementos de acessibilidade física e informativa, colocação equivocada de infraestru- 
tura e mobiliário urbano. O trajeto se iniciou num ponto de ônibus, percorreu vias públicas e terminou junto à escola pública municipal do bairro, num total de 250 metros.

Os resultados da avaliação pós-ocupação com o uso dos métodos: Active Design e do Passeio Acompanhado permitiram elaborar croquis de anotações e levantamentos das percepções vividas na área de estudo. As ilustrações apresentam o cenário real encontrado e as soluções projetuais universais aplicadas sobre ele. As propostas, além de contemplarem as exigências da NBR 9050/2015, qualificam os ambientes. O uso de croquis sobre imagens reais tem a função didática de futuro compartilhamento com a comunidade.

Os resultados obtidos, através dos estudos iniciais apresentados neste trabalho, permitem as seguintes conclusões:

a. a percepção dos usuários em relação à importância dos atributos de caracterização da infraestrutura das calçadas e travessias das vias deve ser considerada, pois permite estabelecer uma ordem de prioridade das variáveis de definição dos aspectos de conforto e segurança;

b. a avaliação técnica se mostrou eficiente e de fácil aplicação para o levantamento das condições atuais da infraestrutura das calçadas e travessia das vias, bem como suas características de projeto (concepção).

Embora tenha havido essa perspectiva de olhar dirigido à escala da rua e dos passeios, em que as pessoas vivem uma escala urbana mais íntima e cotidiana, torna-se mais clara a conexão dessa escala com as demais. Essa relação coloca a escala da rua e das calçadas como um tipo de consequência inevitável de um sistema de espaços livres sem planejamento integrado. 


\section{CONSIDERAÇÕES FINAIS}

As cidades brasileiras contam com uma série de contradições espaciais, que vão desde questões ligadas ao planejamento da cidade e suas conexões com a região, passando pela mobilidade regional-urbana, a implantação de espaços públicos, chegando até o nível da rua e das calçadas. O resultado é que essa ação de urbanização, muitas vezes, é realizada de forma desigual, privilegiando investimentos públicos em alguns lugares de interesse específico, nem sempre justificáveis, e deixando uma parcela importante da cidade e de sua sociedade em situação precária no que diz respeito ao recebimento de serviços urbanos básicos.

Nesse cenário, um sistema de espaços livres, em suas diferentes categorias e escalas, bem, planejados, desenhados e implantados oferece um papel importante no desenho da cidade, oferecendo oportunidades de convívio e de ampliação da qualidade de vida das pessoas. Indo de parques e praças até os passeios públicos, o sistema de espaços livres representa um elemento importante para a vida urbana.

Neste trabalho, apresentamos em exercício de abordagem em três escalas do sistema de espaços livres de Criciúma, buscando trazer o olhar sistêmico necessário para essa leitura, incluindo a vida que faz parte e movimenta a paisagem. Neste primeiro momento, foi possível reforçar a relevância de cada escala, a partir da aplicação de suas abordagens metodológicas particulares, ficando como grande desafio ainda o aprofundamento dessa integração de leitura da paisagem multiescalar.

Esses resultados preliminares indicam, de forma geral, que o papel da aplicação adequada das políticas públicas, em seus níveis condizentes, é fundamental. Leis e estudos fragmentados existem e têm grande força transformadora. Porém, quando olhamos de perto cada uma das escalas, observamos que não há o cuidado adequado na aplicação, na regulamentação e no acompanhamento das aplicações delas.

Esse fato se expressa de forma mais clara na dimensão local, gerando espaços descontínuos, desconexões entre áreas de uso 
público, desconexão de pessoas que não possuem um sistema de mobilidade que atenda a seus interesses multiescalares, seja para ir trabalhar, encontrar amigos na praça, fazer comprar ou ir a casa de um vizinho próximo. Embora a paisagem nos mostre um retrato de toda a realidade da gestão, indica-nos sua desfragmentação sistêmica.

É neste sentido que a proposta de olhar em várias escalas nos permitiu abrir essa visão do todo sistêmico. Mas, por outro lado, deixou claro que há dificuldades de integrar métodos de análise e de apresentação de resultados. Essa é tarefa para se seguir adiante nos estudos sobre os sistemas de espaços livres em nosso grupo.

Outra perspectiva importante nesta abordagem seria o fortalecimento das relações, em complementaridade, das ações teórico-técnicas e participativas, incluindo definitivamente a dinâmica de troca sustentável de conhecimentos com a população que vive nos lugares. Essa proposta amplia a questão da leitura espacial para além das adequações técnicas e insere o ambiente da cidade como um lugar de aprendizado coletivo, assumindo um papel de agente direto e intencional na formação de seus cidadãos, que se sentem incentivados a tomarem para si a responsabilidade, e a vontade de realizar ações que fortaleçam a cidadania. Viabilizar acesso igualitário ao sistema de espaços livres multiescalar é um dos caminhos que podem transformar nossas cidades.

\section{REFERÊNCIAS}

ABNT. NBR-9050: Acessibilidade a edificações, mobiliário, espaços e equipamentos urbanos. Associação Brasileiras de Normas Técnicas, Rio de Janeiro; ABNT, 2015.

ACTIVE DESIGN: SHAPING THE SIDEWALK EXPERIENCE. Disponível em: <https://www1.nyc.gov/assets/planning/download/pdf/plans-studies/ active-design-sidewalk>. Acesso em: 15 dez. 2016. 
COHEN, Regina; DUARTE, Cristiane Rose. Pesquisa e projeto de espaços públicos: rebatimentos e possibilidades de inclusão da diversidade física no planejamento das cidades. In: Projetar 2005 - II Seminário sobre Ensino e Pesquisa em Projeto de Arquitetura, 2005, Rio de Janeiro. Anais do II PROJETAR. 2005.

DISCHINGER, Marta; BINS ELY, Vera Helena Moro; BORGES, Monna Michelle F. C. Manual de acessibilidade espacial para escolas: o direito à escola acessível. Brasília: Ministério da Educação, Secretaria de Educação Especial, 2009.

DISCHINGER, Marta; et al. A importância do desenvolvimento de métodos de avaliação de acessibilidade espacial - estudo de caso no Colégio de Aplicação - UFSC. Núcleo de Pesquisa em Tecnologia da Arquitetura e Urbanismo - NUTAU. São Paulo: USP, 2006.

DISCHINGER, Marta. Designing for all senses: accessible spaces for visually impaired citizens. Göteborg, Suécia, 2000 - Department of Space and Process, School of Architecture, Chalmers University of Technology.

GADOTTI, Moacir. Município que educa: história, conceitos e fundamentos. Rede Social Município que Educa. São Paulo: Instituto Paulo Freire, 2009.

GPSEL-CRICIÚMA - Grupo de Pesquisa Sistemas de Espaços Livres de Criciúma. Relatório de Visitas Técnicas: 2016-2017. Curso de Arquitetura e Urbanismo, Universidade do Extremo Sul Catarinense/UNESC, 2017.

LIMA, A. M. L. P.; CAVALHEIRO, F.; NUCCI, J. C.; SOUSA, M. A. L. B.; FIALHO, N. O.; DEL PICCHIA, P. C. D. Problemas de utilização na conceituação de termos como espaços livres, áreas verdes e correlatos. In: Congresso Brasileiro sobre Arborização Urbana, II; Encontro Nacional sobre 
Arborização Urbana, Anais... São Luís: Sociedade Brasileira de Arborização Urbana, 1994. p. 539-553.

MACEDO, Silvio S.; CUSTÓDIO, Vanderli et al. Os sistemas de espaços livres da cidade contemporânea brasileira e a esfera de vida pública: considerações preliminares. In: Encúentro de Geógrafos de América Latina, 12․, 2009, Montevideo. Anais do XII EGAL, 3- 7 abril. Montevideo: Universidad de la República, 2009. p. 1-12.

MAGNOLI, Miranda. Espaços livres e urbanização. Tese (Livre-docência) - FAUUSP, São Paulo, 1982.

PADARATZ, Rejane; BINS ELY, Vera Helena M.; DISCHINGER, Marta. Acessibilidade e inclusão no ensino para melhoria da qualidade de vida urbana. In: Anais do 10 Congresso Luso-Brasileiro para o Planejamento Urbano, Regional, Integrado e Sustentável. São Paulo: USP, 2005.

PAMPLONA, Maurício. SIERVI, Elizabeth de. Sistema de espaços livres na Região da Grande Santa Luzia, Criciúma/SC: Contribuições para inserção da comunidade na qualificação do espaço urbano municipal. In: 13o Encontro Nacional de Ensino de Paisagismo em Escolas de Arquitetura e Urbanismo no Brasil, Salvador, 2016.

PATRÍCIO, Z. M. Introdução à prática de pesquisa socioambiental. Apostila. Curso de especialização em Gestão de Recursos Hídricos. Departamento de Engenharia Sanitária e Ambiental - UFSC, 2005.

QUEIROGA, Eugenio Fernandes. Da relevância pública dos espaços livres um estudo sobre metrópoles e capitais brasileiras. Rev. Inst. Estud. Bras., São Paulo, n. 58, p. 105-132, jun. 2014. 
ROBBA, F.; MACEDO, S. S. Praças brasileiras. Estudos Geográficos: Revista Eletrônica de Geografia, Rio Claro, v. 2, p. 87-88, jul./dez. 2004.

SAVI, Aline Eyng. Espaços livres públicos: acessibilidade para todos. Projeto de Pesquisa PIBIC/CNPQ/UNESC. Criciúma, 2016.

SANTOS, Emmanuel Antonio dos. Planejamento regional e paisagem: instância integradora, movimento, simultaneidade, interação escalar, projeto. Pós. Revista do Programa de Pós-Graduação em Arquitetura e Urbanismo da FAUUSP, São Paulo, n. 26, p. 18-33, dec. 2009. Disponível em: <https://www.revistas.usp.br/posfau/article/view/43637>. Acesso em: 17 ago. 2017.

SANTOS, Milton. Pensando o espaço do homem. 4. ed. São Paulo: Hucitec, 1997.

SAVI, Aline Eyng. SIERVI, Elizabeth de. PAMPLONA, Maurício. CIDADE EDUCADORA E SISTEMAS DE ESPAÇOS LIVRES NA ABORDAGEM DA ACESSIBILIDADE: estudo de caso na região da grande Santa Luzia, em Criciúma. Relatório de Pesquisa - Grupo de Pesquisa Sistema de Espaços Livres em Criciúma/UNESC. 2017.

SIERVI, Elizabeth M. C. de. Instrumentos de levantamento e tratamento de dados para apoio ao processo projetual de arquitetura e urbanismo: subsídios teórico-metodológicos. Pesquisa de Pós Doutorado - Relatório Circunstanciado. Universidade Federal de Santa Catarina, UFSC, 2015.

SIERVI, Elizabeth Maria Campanella de. Contribuição das áreas protegidas no sistema de espaços livres da Grande Santa Luzia, Criciúma/SC. Projeto de Pesquisa PIC/UNESC. Criciúma, 2016a. 
SIERVI, Elizabeth Maria Campanella de. Espaços livres públicos na cidade Educadora: Conceitos, metodologias e instrumentos aplicados ao contexto da acessibilidade na Arquitetura e do Urbanismo em área piloto da Grande Santa Luzia, em Criciúma, Santa Catarina. Projeto de Pesquisa PIBIC/CNPQ/UNESC. Criciúma, 2016.

STIFELMAN, Anelise Grehs. Alguns aspectos sobre o licenciamento ambiental da mineração no Brasil. In: Congresso Nacional de Direito Ambiental: paisagem, natureza e direito, 10., 2005, São Paulo. Anais. São Paulo: IMESP, 2005. v. 1, p. 533-550.

TUAN, Yi-Fu. Espaço e lugar: a perspectiva de experiência. São Paulo: Difel, 1983.

VARGAS, Maria Auxiliadora Ramos. Moradia e pertencimento: a defesa do Lugar de viver e morar por grupos sociais em processo de vulnerabilização. Cad. Metrop., São Paulo, v. 18, n. 36, p. 535-558, dez. 2016. Disponível em: <http://www.scielo.br/scielo.php?script=sci_arttext\&pid=S223699962016000200535\&lng=en\&nrm=iso >. Acesso em: 15 jul. 2017. 